\title{
MODELLING A FLUIDIZED BED REACTOR BY INTEGRATING VARIOUS SCALES: PORE, PARTICLE, AND REACTOR
}

\author{
Robert Macias ${ }^{1}, J_{\text {Jan }}$ Maya $^{1}$, Farid Chejne ${ }^{1}$, Zainab Afailal ${ }^{2}$, and Jesús Arauzo Pérez ${ }^{2}$ \\ ${ }^{1}$ Universidad Nacional de Colombia Sede Medellin \\ ${ }^{2}$ Universidad de Zaragoza
}

May 27, 2020

\begin{abstract}
This work proposes a novel population-balance based model for a bubbling fluidized bed reactor. This model considers two continuum phases: bubble and emulsion. The evolution of the bubble size distribution was modeled using a population balance, considering both axial and radial motion. This sub-model involves a new mathematical form for the aggregation frequency, which predicts the migration of bubbles from the reactor wall towards the reactor center. Additionally, the reacting particles were considered as a lagrangian phase, which exchanges mass with the emulsion phases. For each particle, the variation of the pore size distribution was also considered. The model presented here accurately predicted the experimental data for biochar gasification in a lab-scale bubbling fluidized bed reactor. Finally, the aggregation frequency is shown to serve as a scaling parameter.
\end{abstract}

\section{Hosted file}

Manuscript_final.pdf available at https://authorea.com/users/327056/articles/454730modelling-a-fluidized-bed-reactor-by-integrating-various-scales-pore-particle-andreactor 